Research Article

\title{
The Optimization Analysis of Sports Industry Experience Consumption Ability under the Theory of Aesthetic Economy
}

\author{
Rongrong Wang (iD \\ Wuhan Sports University, Wuhan 430070, Hubei, China \\ Correspondence should be addressed to Rongrong Wang; wangrongrong@whsu.edu.cn
}

Received 9 August 2021; Accepted 1 October 2021; Published 3 November 2021

Academic Editor: Daqing Gong

Copyright (C) 2021 Rongrong Wang. This is an open access article distributed under the Creative Commons Attribution License, which permits unrestricted use, distribution, and reproduction in any medium, provided the original work is properly cited.

The consumption ability of the sports industry is an indicative index of sports economic development, and aesthetic economic theory plays a guiding role in this content. At present, the evaluation method of sports industry consumption ability is too single, lack of the comprehensive evaluation model, and cannot carry out accurate evaluation. This study proposes a comprehensive improved algorithm based on K-mean preprocessing, which can evaluate and judge the consumption capacity of the sports industry with the help of aesthetic economic theory, and provides support for the later formulation of experience consumption strategy. MATLAB simulation results show that the accuracy of the calculation results of the improved algorithm proposed in this study is more than $95 \%$, and the fit between consumption ability evaluation indexes is more than $98 \%$, which is better than the traditional algorithm as a whole. Therefore, the comprehensive improved algorithm can optimize the consumption capacity of the sports industry.

\section{Introduction}

Sports consumption ability is one of the important abilities to judge the development of sports, and it is also an indirect index of the development of the sports industry. With the rapid development of social economy, people have higher and higher requirements for sports products, which also promotes the development of the sports industry to a comprehensive aspect. In order to obtain more social resources, different sports industries continue to compete and compete. As a new theory, aesthetic economy has been widely used in the sports industry, since it was put forward, and has become an important theory to promote sports consumption. Some scholars believe that aesthetic economy gives new impetus to the sports industry and promotes the development of sports consumption ability. Some scholars believe that aesthetic economy guides the development of the sports industry and drives sports consumption from a macroperspective. Therefore, aesthetic economy plays an important role in guiding and promoting sports consumption ability. However, the role of aesthetic economy in promoting sports consumption ability has not been fully played, mainly due to the lack of the accurate evaluation model and algorithm. The existing mathematical algorithms cannot deal with the massive data in sports consumption, cannot accurately calculate the sports consumption ability, and cannot integrate the aesthetic economic theory with the judgment of sports consumption ability. Therefore, this study proposes an evaluation model based on K-means to analyze sports consumption ability under the guidance of aesthetic economic theory, in order to provide the theoretical support for sports consumption decision-making.

\section{The Influencing Factors}

The experience consumption ability of the sports industry involves many factors. Only by comprehensively analyzing the experience consumption ability under the theory of aesthetic economy, can we find out its main influencing factors and indicators, so as to optimize the experience consumption ability.

2.1. Determination of Influencing Factors. Some research results show that the key of sports industry experience is to experience products and consumers' experience and to improve consumers' experience consumption intention. At 
the same time, in order to more accurately judge the experience consumption ability of sports industry, the evaluation of experience consumption ability should be the "NIMBY effect" and calculate the reasonable experience consumption demand. Therefore [1], experience coefficient and demand coefficient are one of the influencing factors of sports industry's experience consumption ability. Some scholars believe that the individual differences and cultural level of the experiencer have a significant impact on the experience demand, which increases the judgment error of experience consumption ability. Standardization [2] can simplify the complexity of experience consumption ability judgment and improve the evaluation accuracy of experience consumption ability.

Some scholars [3] believe that forward-looking prediction of experience demand and predictive choice of experience products [4] can increase consumer experience satisfaction and reduce the error between the theoretical judgment and actual effect of the experience effect. Therefore, the interaction coefficient and the degree of aesthetic integration are other influencing factors of the experience consumption ability, and the results are given in Table 1.

2.2. Mathematical Description of Influencing Factors. Assuming that the relevant data of sports industry experience products are independent data, the evaluation method of experience consumption ability is the comprehensive evaluation method, and the experience behavior of consumers is not concentrated [5]; then, the consumption ability of sports industry experience can be monitored and judged. Among them [6], the monitoring indicators include experience coefficient, interaction coefficient, demand coefficient, and aesthetic integration degree.

(1) Assuming that the index set of experience consumption ability is $m$, different experience products correspond to different consumption ability $I$, that is [7], the data sent by evaluation devices such as vision, heartbeat, emotion, psychology, and scoring in sports product experience, and the device ID of sending data $I$ is different. The results are shown in Figure 1.

(2) If $N$ is the information collection of sports consumption ability, $i$ is the number of experience data sent by the device, $j$ is the ID number of the device, $k$ is the judgment information of experience result ( atisfied $=1$, dissatisfied $=0$ ), $l$ is the sequence of experience products, and $m$ is the collection terminal of experience data, then the information of sports consumption ability can be described as $N=\sum_{i=0}^{n} N_{i} \cap \sum_{j=0}^{n} N_{j} \cap \sum_{k=0}^{n} N_{k} \cap \sum_{l=0}^{n} N_{l}$, where $i, j, k, l, m=(1,2, \ldots \ldots, n), n$ is a natural number.

(3) The integration of the aesthetic value and experience product

The integration of sports industry experience data and aesthetic value can improve the value of experience. Tai et al. [3] enhanced the exchange value and use value of products. Because of the exchange value and use value of different experience products, we can use the integration degree of $\cup_{i=1}^{n}\left(m_{i} \cdot I_{i}\right)$ aesthetics, interaction value, and use value. Among them, $m$ is the data of the exchange value and use value of experience products, and $I$ send information data. In order to ensure the accuracy of the processing results [8], it is necessary to restrict the degree of aesthetic value fusion:

$$
S=\sum_{j=0}^{n} \bigcup_{i=1}^{n}\left(m_{i} \cdot I_{i}\right)_{j}
$$

Among them, $S$ is the fusion degree of the aesthetic value. The relationship between sports industry experience data and consumer demand is $n: n$, and the calculation results are affected by many factors. In order to realize the quantitative analysis of data [9], Euclidean distance similarity calculation can be carried out to improve the accuracy of $S$ data processing. The calculation formula is as follows:

$$
S(A, B)=\frac{|A \subseteq B|}{\sum_{j=0}^{n} \cup_{i=1}^{n}\left(m_{i} \cdot I_{i}\right)_{j}} .
$$

Among them, A is the function of the experience product, and B is the demand of consumers. Because consumers may increase the use frequency of the product when they are satisfied with the product [10], they can obtain the indirect satisfaction of the product by calculating the use frequency of the product. Assuming that the number of occurrences of the product is $G$ and the order of occurrence is $H$ [11], then the ranking result of satisfaction of the product is $R$. The specific calculation formula is as follows:

$$
R=\frac{G_{i j}}{\prod G_{i}+G_{j}}
$$

where $G_{i j}$ is the number of times that $J$ consumers experience $i$ products, and $G_{j}$ is the total number of times.

(4) The interaction coefficient, experience coefficient, demand coefficient, and aesthetic integration degree of experience products are judged based on the experience product sequence L, so as to verify the error between theoretical measurement and actual measurement and evaluate the accuracy of judgment of experience consumption ability.

(5) The order of sports industry experience [12] is distributed by the experience center as a whole, and the corresponding weight $H$ and frequency $G$ constraints are set to generate the experience list of sports products.

(6) Assuming that the interaction coefficient $x$, experience coefficient $y$, demand coefficient $z$, and aesthetic integration degree $o$ of sports products meet the requirements, the correlation coefficient meets the 
TABLE 1: Influencing factors of experience consumption ability under the theory of aesthetic economy.

\begin{tabular}{lccc}
\hline Influence factor & Describe & Influence factor & Describe \\
\hline $\begin{array}{l}\text { Experience } \\
\text { coefficient }\end{array}$ & $\begin{array}{c}\text { Experience consumption related data and experience } \\
\text { product related data }\end{array}$ & $\begin{array}{c}\text { Demand } \\
\text { coefficient }\end{array}$ & $\begin{array}{c}\text { The satisfaction of experience products to } \\
\text { users' needs }\end{array}$ \\
\hline $\begin{array}{l}\text { Interaction } \\
\text { coefficient }\end{array}$ & The degree of interaction between consumers and \\
sports products & & \\
\hline
\end{tabular}

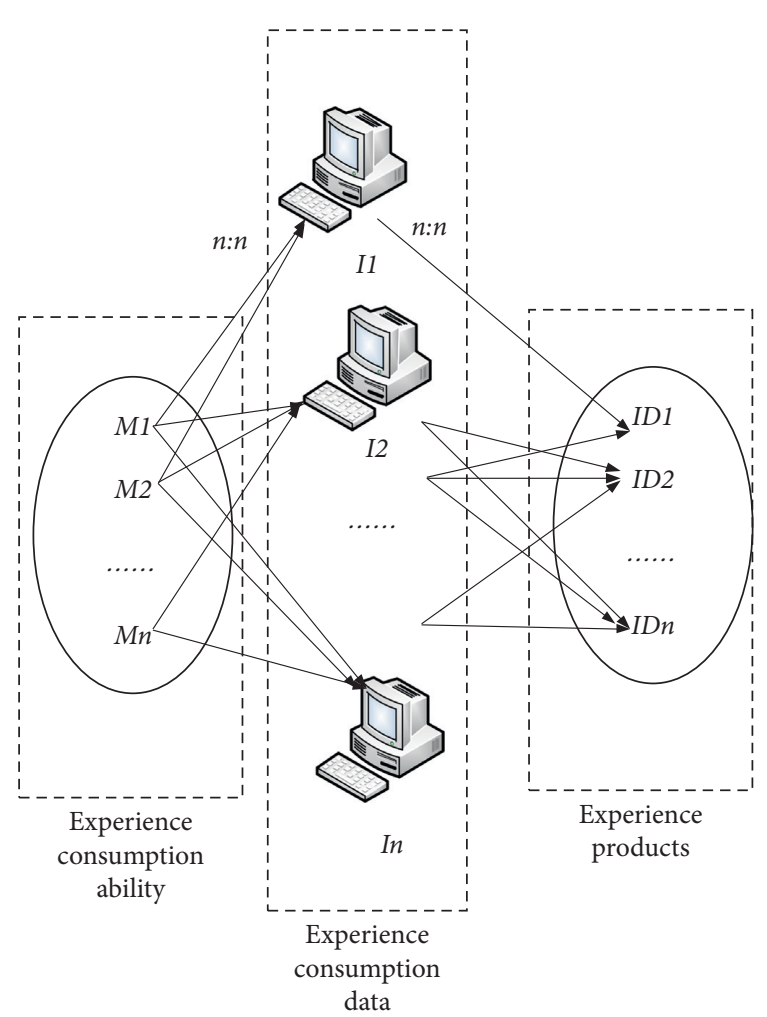

FIGURE 1: The relationship among experience consumption ability index, experience data, and sports products.

expected constraints, and then, the relevant consumption ability evaluation can be carried out.

\section{The Construction of the Evaluation Model}

3.1. Construction of the Model Algorithm. Because of the dynamic fit between sports products and consumer satisfaction, this study constructs the artificial fish swarm algorithm to evaluate and analyze the consumption ability. The evaluation content of the interaction coefficient $x$, experience coefficient $y$, demand coefficient $z$, aesthetic integration degree $o$, and the final consumption ability is calculated repeatedly. First, the experience data are standardized, and the information $I$ is normalized into a vector $|I|$, and then, the eigenvalues of correlation matrix $D$ are calculated to obtain the optimal fitting results. In addition, due to the large individual differences of consumers [13], it is easy to affect the final judgment results, so we need to use metropolis acceptance criteria to constrain, so as to reduce the impact of individual differences on the results and reduce the redundant information generated by different experience product switching.
Suppose that the experience order of experience product is $l_{k}$ and the experience order changes from $l_{k}$ to $l_{k+1}$, then the sports effect of consumers is

$$
P_{l k}=\exp \left[f\left(l_{k+1}\right)-\frac{f\left(l_{k}\right)}{l_{k}}\right] \bullet \operatorname{step}(r) .
$$

Among them, $f\left(l_{k+1}\right)$ is the consumption ability $l_{k+1}$ in the order of experience, step $(r)$ is the experience frequency in different degrees, and $r$ is the European distance value.

The constraint conditions $P_{l k}$ in the following formula are tested, and the test formula is as follows:

$$
P_{l k} \begin{cases}\lim f(\infty), & f\left(l_{k+1}\right)=1, \\ \exp \left\{f\left(l_{k+1}\right)-\frac{f\left(l_{k}\right)}{T_{k}}\right\}, & f\left(l_{k+1}\right)<f\left(l_{k}\right), \\ \lim f\left(\frac{1}{\infty}\right), & f\left(l_{k+1}\right)=0\end{cases}
$$

3.2. Evaluation Accuracy Design. The accuracy of evaluation is the judgment index of whether the construction of the sports industry experience consumption ability model meets the requirements, which reflects the consistency between the theoretical results of the model and the actual results. The accuracy design is usually represented by an appropriate function, which can guide the iterative calculation direction of artificial fish swarm. If the deviation between the theoretical value and the actual value is large, it will affect the safety of the evaluation of experience consumption ability, so the initial threshold should be set, which is generally set to 0.01 . Based on the evaluation of experience consumption ability, this study improves the security of sharing and achieves the maximum consistency between the theoretical value and the actual value, so the initial threshold is set to 0.001. The specific formula of moderate function is as follows:

$$
f=\min \left\{\max _{k \in 1,2,3 \ldots, m} \frac{\left(F_{k}\right)+\left(F_{k-1}\right)}{\sum_{i \in 1,2, \ldots n} \max \left(k_{0}-k_{i}\right)}\right\},
$$

where $F_{k}$ is the difference between the actual value and $k_{0}$ is the theoretical value; initial data, $k_{i}$ is the $i$ data.

3.3. Fitting Item Design. The fitting items include interaction coefficient $x$, experience coefficient $y$, demand coefficient $z$, and aesthetic integration degree $o$. The fitting items produce a comprehensive evaluation on the analysis of experience consumption ability [14], which is also the evaluation result 
under the aesthetic economic theory. The calculation formula of the fitting term is as follows:

$$
\sum_{k=x, y, z, o, i=1}^{n} P_{l_{k}} \begin{cases}\sum_{i=0}^{n} N_{i} \cap \sum_{j=0}^{n} N_{j} \cap \sum_{k=0}^{n} N_{k} \cap \sum_{l=0}^{n} N_{l}, & f_{k} \leq f_{\max }, \\ k_{i} \frac{\left(f_{k}-f_{\min }\right)}{\left(f_{k}-f_{\min }\right)}, & f_{k}>f_{\min } .\end{cases}
$$

When the result of experience judgment $=1, f_{\min }$ is that the consumer is very satisfied, which is the lowest satisfaction of each sports product experience; $f_{\max }$ is the highest satisfaction of the existing sports products; $f_{k}$ is the degree of consumer satisfaction of each product sports.

3.4. Iterative Calculation Process of Sports Consumption Ability. Based on the above analysis, the establishment steps of the data open experience consumption ability guarantee system under the theory of aesthetic economy are obtained.

(1) Set the initial sports industry experience dataset $N$, interaction coefficient $x$, experience coefficient $y$, demand coefficient $z$, and aesthetic fusion degree $o$, and set all the experience result judgment information $k$ to 0 and the initial threshold of sports industry experience data accuracy 0.001 .

(2) When all the experience devices are completed, the artificial fish swarm calculation will be terminated, and the next step will be carried out.

(3) According to Metropolis acceptance criteria, the experience demand and fitting degree are calculated; if the calculation results exceed the threshold of parameters, the data are set as invalid operation.

(4) The consumption satisfaction is calculated repeatedly, and the consumption ability of the object is obtained.

\section{Judgment of Sports Industry Experience Consumption Ability}

4.1. Introduction to Experience Consumption Cases of Sports Industry. Lan [15] took the VR simulation sports product exhibition held in Zhengzhou in December 2020 as an example to calculate the consumption capacity of sports products. Compare the theoretical consumption capacity with the actual consumption capacity [16], compare the accuracy and satisfaction of the calculation results of consumption capacity, as well as the fitting degree between different indicators, and set the calculation error accuracy to 0.01 . Among them, the theoretical consumption capacity is calculated by computer, and the actual consumption capacity is based on expert investigation.

4.2. Consumption Ability Test Index. In order to ensure the validity of the test results, 100 iterations of the sports industry experience are conducted, and the results are output

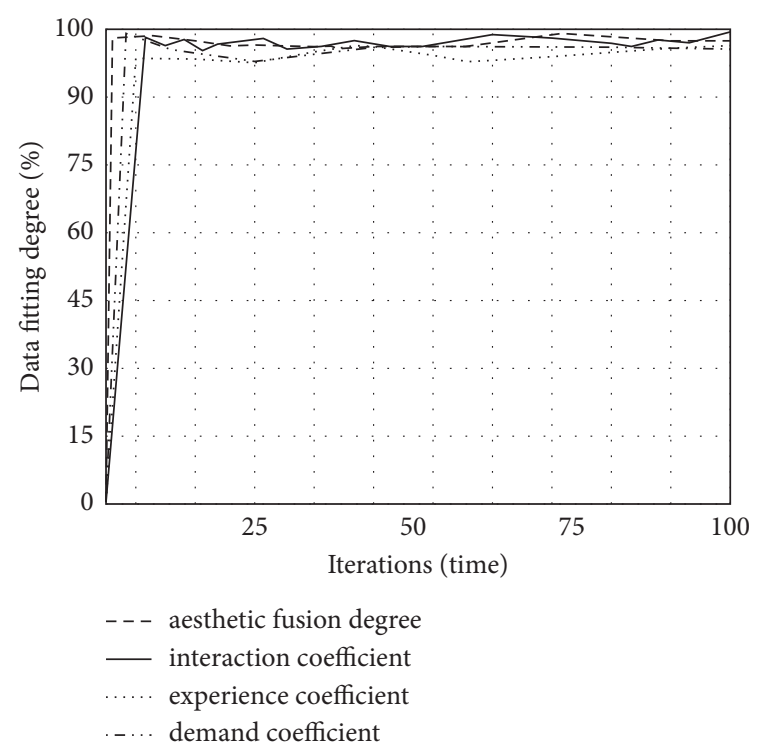

Figure 2: Product data processing results.

in the form of graphics. After 100 iterations, the clustering degree results of interaction coefficient $\sum_{i=0}^{n} N_{i} \cap \sum_{j=0}^{n} N_{j} \cap \sum_{k=0}^{n} N_{k} \cap \sum_{l=0}^{n} N_{l}$, experience coefficient, demand coefficient, and aesthetic fusion degree are obtained. The results show that after 100 iterations, each index of consumption capacity reaches more than $90 \%$ of the fitting degree, which indicates that the fitting degree of sports industry experience products and consumer demand is good. However, after 100 iterations, some data fitting is not good, which fully shows that individual differences of consumers have a greater impact on the results. However, under the treatment of Euclidean distance, satisfactory fitting results are obtained. The results are shown in Figure 2.

4.3. The Accuracy of Experience Consumption Ability Evaluation. After 100 times of simulation analysis on the accuracy of the interaction coefficient, experience coefficient, demand coefficient, and aesthetic fusion degree, the safety of the interaction coefficient is maintained at more than $98 \%$, the safety of experience coefficient is maintained at more than $92 \%$, the demand coefficient is maintained at more than $90 \%$, and the promotion coefficient is maintained at more than $93 \%$. The accuracy of the demand coefficient and experience consumption ability judgment is related to the accuracy of experience consumption ability evaluation of the whole sports industry, and it is also an important index of the consumption ability evaluation model. The experience and demand in the evaluation of experience consumption ability is the basis of ability optimization, but the fitting of the index remains above $92 \%$, which indicates that the fitting accuracy between experience products and demand of the whole sports industry is good. Relatively speaking, the judgment accuracy of the aesthetic integration degree is low because the application degree of aesthetic economic theory in the evaluation of sports industry experience consumption ability is low, but the accuracy of more than $90 \%$ still shows 


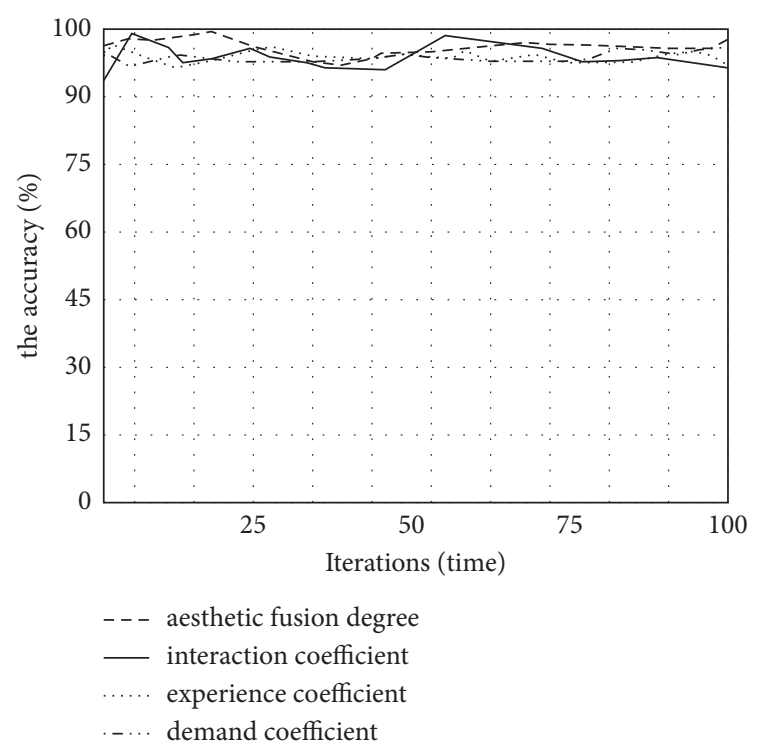

FIGURE 3: The accuracy of interaction coefficient, experience coefficient, demand coefficient, and aesthetic fusion degree.

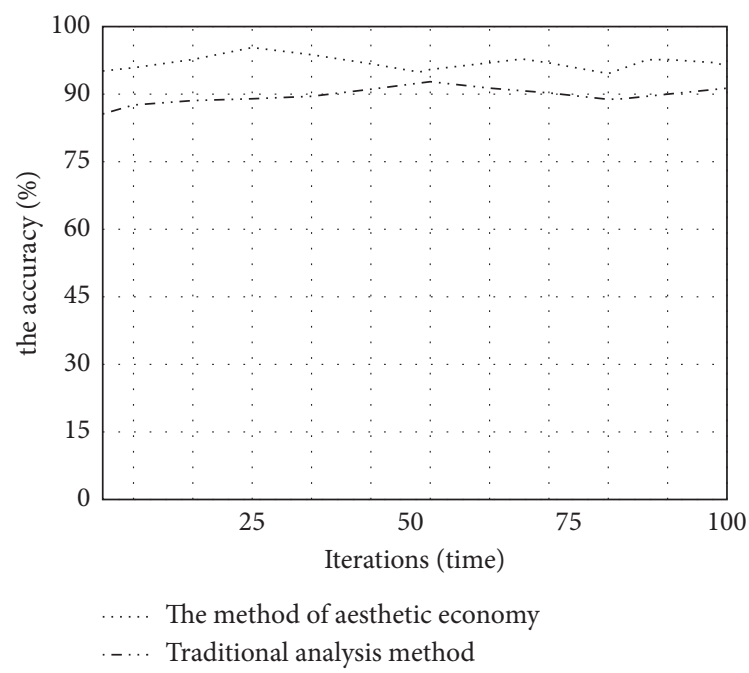

Figure 4: Comparison of two different evaluation methods.

that the aesthetic economic theory plays an obvious role in guiding experience consumption. The results are shown in Figure 3.

\subsection{Optimization Degree of Experience Consumption Ability} Evaluation. In view of the optimization degree of experience consumption ability of the sports industry under the theory of aesthetic economy, it is found that the overall degree of data is above $90 \%$, which improves the evaluation effect of traditional methods by $10 \%$, mainly due to the increase of the integration degree of aesthetic economy theory, the increase of data fitting degree, and the simplification of relevant equipment data, which makes the calculation effect rise as a whole. Relatively speaking, the accuracy between the evaluation under the theory of aesthetic economy and that of traditional methods is relatively high, which remains above $80 \%$. However, under the aesthetic economy, the evaluation effect of sports industry experience consumption ability is better, which remains above $95 \%$, meeting the actual evaluation requirements. The results are shown in Figure 4.

\section{Conclusions}

This study analyzes the evaluation of experience consumption ability in sports industry experience and constructs a consumption ability evaluation method based on the artificial fish swarm algorithm and metropolis acceptance criteria $[10,11]$. It initially solved the problem that the sports industry experience effect cannot be accurately evaluated. Through the analysis of the interaction coefficient $x$, experience coefficient $y$, demand coefficient $z$, and aesthetic integration degree $o$, it is found that the consumption ability index has reached more than $90 \%$ fitting degree after 100 iterations, which indicates that the fitting degree of sports industry experience products and consumer demand is good. However, after 100 iterations, some data fitting is not good, which fully shows that individual differences of consumers have a greater impact on the results. However, under the treatment of Euclidean distance, satisfactory fitting results are obtained. After 100 times of simulation analysis on the accuracy of the interaction coefficient, experience coefficient, demand coefficient, and aesthetic fusion degree, the safety of the interaction coefficient is maintained at more than $98 \%$, the safety of experience coefficient is maintained at more than $92 \%$, the demand coefficient is maintained at more than $90 \%$, and the promotion coefficient is maintained at more than $93 \%$. According to the optimization degree of experience consumption ability of sports industry under the theory of aesthetic economy, it is found that the overall degree of data is above $90 \%$, and the evaluation effect of traditional methods is improved by $10 \%$. Therefore, the evaluation method of sports industry experience consumption ability under the theory of aesthetic economy is better.

\section{Data Availability}

No data were used to support this study.

\section{Conflicts of Interest}

The authors declare that they have no conflicts of interest.

\section{References}

[1] Y. Li, M. Xu, X. Wen, and D. Guo, "The role of internet search index for tourist volume prediction based on GDFM model," Tehnicki vjesnik-Technical Gazette, vol. 27, no. 2, pp. 576-582, 2020.

[2] K. Hornung and M. Hornung, "ERP systems in croatian enterprises," Tehnicki vjesnik-Technical Gazette, vol. 27, no. 4, pp. 1277-1283, 2020.

[3] F. Tai, J. Yan, and Z. Yu, "Research on sports consumption upgrading in China from the perspective of aesthetic 
economic theory," Journal of Capital Institute of physical education, vol. 32, no. 2, pp. 69-74, 2020.

[4] L. Kosolini and N. Lu, "Changes in aesthetics, economy and ideology (1930-1945),” Drama, vol. 12, no. 4, pp. 5-14, 2017.

[5] M. Lazar, D. Javoršek, and A. Hladnik, "Study of camera spectral reflectance reconstruction performance using CPU and GPU artificial neural network modelling," Tehnicki vjesnik-Technical Gazette, vol. 27, no. 4, pp. 1204-1212, 2020.

[6] K. Ashoka and S. Shanmugathas, "Factors influencing the mark-up decisions of infrastructure projects in developing countries: the case of Sri Lanka," Journal of System and Management Sciences, vol. 8, no. 2, pp. 1-25, 2018.

[7] X. Li, "Aesthetic production in the age of cultural creativity," Chinese literary criticism, vol. 13, no. 3, pp. 95-102, 2017.

[8] M. R. I. Chowdhury, M. Rahman, and T. A. Srabon, "Sustainable construction performances: challenge and limitation to successful adoption in construction industry," Journal of System and Management Sciences, vol. 8, no. 2, pp. 26-46, 2018.

[9] L. Chen, "Tourism aesthetics in the era of aesthetic economy," Contemporary economy, vol. 13, no. 10, pp. 67-69, 2020.

[10] D. Lapkova, "Education in professional defense-possibilities of classification of training level with the help of impulse," Journal of System and Management Sciences, vol. 8, no. 1, pp. 23-44, 2018.

[11] S. Ahmed and M. I. Hoque, "Barriers to implement building information modeling (BIM) to construction industry: a review," Journal of System and Management Sciences, vol. 8, no. 1, pp. 45-60, 2018.

[12] D. Cason, M. Lee, J. Lee, I.-S. Yeo, and E. J. Arner, "The impact of legalization of sports gambling: how motivation, fandom, and gender influence sport-related consumption," International Journal of Sport Communication, vol. 13, no. 4, pp. 643-654, 2020.

[13] S. Chan-Olmsted and D. H. Kwak, "Fantasy sport usage and multiplatform sport media consumption," Sport Marketing Quarterly, vol. 29, no. 3, pp. 204-214, 2020.

[14] C. A. Goodhew, T. L. Perry, and N. J. Rehrer, "Factors influencing energy drink consumption in participants and viewers of extreme sports," Journal of Nutrition and Metabolism, vol. 2020, Article ID 9382521, 6 pages, 2020.

[15] Y. Lan, "The development of leisure sports consumption of urban residents under the view of marine ecological environment," Journal of Coastal Research, vol. 104, pp. 863-866, 2020.

[16] D. Whitburn, A. Karg, and P. Turner, "The effect of digital integrated marketing communications on not-for-profit sport consumption behaviors," Journal of Sport Management, vol. 34, no. 5, pp. 417-434, 2020. 